\title{
ANALYZING THREE GENOTOXIC IMPURITIES OF ATORVASTATIN CALCIUM EMPLOYING GC-MS SINGLE QUAD DETECTOR WITH ELECTRON IMPACT TECHNOLOGY
}

\author{
Mohinish Sahai ${ }^{1, \bowtie}$, Nayakanti Devanna ${ }^{2}$ and Rahul Kumar Rajput ${ }^{3}$ \\ ${ }^{1}$ Department of Chemistry, Jawaharlal Nehru Technological University, \\ Anantapur -515002, (Andhra Pradesh) India. \\ ${ }^{2}$ Director, Oil Technological and Pharmaceutical Research Institute, Jawaharlal Nehru \\ Technological University, Anantapur -515002, (Andhra Pradesh) India. \\ ${ }^{3}$ Deparment of Research and Development, Mankind Research Centre, Manesar, \\ Gurugram-122051, (Haryana) India. \\ ${ }^{\square}$ Corresponding Author: mohinish_sahai@rediffmail.com
}

\begin{abstract}
This paper described the first report on GC-MS methodology development and validation for the simultaneous determination of potential genotoxic materials, ethyl methanesulfonate (ELMS), methyl methanesulfonate (MLMS), and isopropyl methanesulfonate (ILMS), in Atorvastatin calcium (ATC). The quantification limits for this methodology ranged from 0.0115 to $0.0767 \mathrm{ppm}$ (ELMS), 0.0111 to $0.0738 \mathrm{ppm}$ (ILMS) and 0.0129 to $0.0858 \mathrm{ppm}$ (MLMS). This methodology has presented excellent eminence parameters for case, linearity (squared correlation coefficient value $>0.990)$, precision for method $(0.6-1.1 \%, n=6)$, ruggedness $(1.1-2.1 \%, n=12)$, system suitability $(5.1-6.1 \%, n=6)$ in relations of relative standard deviation percentage. The recovery values attained in low, medium and high levels of spiked ATC samples were between $87.8 \%$ and $119.1 \%$. The GC-MS methodology demonstrates its versatility in evaluating ELMS, ILMS and MLMS concurrently in ATC 's daily quality assurance evaluations.

Keywords: Impurities, Genotoxic, Atorvastatin Calcium, Gas Chromatography, Mass Spectrometer.
\end{abstract}

RASĀYAN J. Chem., Vol. 14, No.2, 2021

\section{INTRODUCTION}

Alkyl mesylate esters of alcohols with small chains are proved as agents having reactivity with DNA, genotoxicity and possibly carcinogenicity. ${ }^{1-4}$ The practice of using alcohols like ethyl, methyl and isopropyl at any stage of synthesis of pharmaceutical active ingredient or during purification of the pharmaceutical active ingredient, leads to the formation of genotoxic ethyl methanesulfonate (ELMS), methyl methanesulfonate (MLMS), and isopropyl methanesulfonate (ILMS), respectively. ${ }^{5}$ Sometimes, also, these ELMS, MLMS and ILMS are used as starting preparatory materials for pharmaceutical active ingredient synthesis. A toxicological risk threshold value of $1.5 \mu \mathrm{g}$ a day intake of genotoxic impurity is tolerated as is currently the case. ${ }^{6-8 .}$

Atorvastatin calcium (ATC) is a lipid-reducing medication that reduces anomalous levels of cholesterol and other lipids, and ultimately reduces the danger of cardiovascular disorder. ${ }^{9,10}$ Since ATC is given at a maximum allowable dose of $80 \mathrm{mg}$ per day. A permitted intake of genotoxic impurities (ELMS, MLMS and ILMS) in ATC is $18.75 \mathrm{ppm}$ per day. The same quantity value was used as specification limit concentration for ELMS, MLMS and ILMS.

Monitoring and controlling the quality feature of the pharmaceutically active ingredient and formulation products for impurities is just as worthy as signifying efficacy. ${ }^{11-14}$ Quantification of ELMS and MLMS simultaneously in emtricitabine by LC/MS/MS, ${ }^{15}$ methane sulfonic acid by HPLC-UV ${ }^{16}$ and in imatinib mesylate by GC/MS ${ }^{17,18}$ was documented. Quantification of ELMS, ILMS and MLMS simultaneously in 
dapoxetine hydrochloride by GC-ECD, ${ }^{19}$ in rasagiline mesylate by $\mathrm{GC},{ }^{20}$ in lopinavir by GC/MS/MS,${ }^{21}$ and in doxazosin mesylate by GC/MS ${ }^{22}$ were also documented. This paper describes the first report on GC-MS methodology development and validation for the simultaneously ELMS, ILMS and MLMS contaminants determination in ATC.

\section{EXPERIMENTAL}

\section{Instrumentation Employed and Conditions for Quantification}

The analysis and detection of ELMS, ILMS and MLMS were performed on a gas chromatography system (Shimadzu, GC-2010 Plus) fixed with a mass spectrometer (Shimadzu, GCMS TQ8050). The gas chromatographic separation of ELMS, ILMS and MLMS was completed on a DB-5 column with $30 \mathrm{~m}$ length, $0.32 \mathrm{~mm}$ interior diameter and 0.25 -micron film thickness and flow rate of $1.5 \mathrm{ml} / \mathrm{min}$. The functional temperature schedule was started at $40^{\circ} \mathrm{C}$ initially, hold for $5 \mathrm{~min}$, then risen at $12^{\circ} \mathrm{C}$ per min to $105^{\circ} \mathrm{C}$, hold for $0 \mathrm{~min}$ and then again risen at $25^{\circ} \mathrm{C}$ per min to $310^{\circ} \mathrm{C}$, hold for $12 \mathrm{~min}$. Injector temperature was regulated at $285^{\circ} \mathrm{C}$. The quantity of sample injected was $2 \mu \mathrm{L}$ and was performed in split form 1:2. Ion source and interface temperatures were regulated at $230^{\circ} \mathrm{C}$ and $310^{\circ} \mathrm{C}$, respectively. The identification of ELMS, ILMS and MLMS did use a mass spectrometer system in chosen ion mode of monitoring (ions $-80 \mathrm{~m} / \mathrm{z}$ for MLMS, $79 \mathrm{~m} / \mathrm{z}$ for ELMS and $123 \mathrm{~m} / \mathrm{z}$ for MLMS). The data acquirement and processing were examined using Real-Time GCMS solution software (Shimadzu).

\section{Chemicals}

Sun Bio (Bangalore, India) gifted the reference samples of ELMS, ILMS, MLMS and ATC with the potency of $99.9 \%, 100.0 \%, 93.4 \%$ and $99.5 \%$ respectively. Methanol from Merck, India was employed as diluent.

\section{ELMS, ILMS and MLMS Solutions}

The stock ELMS, ILMS and MLMS solution was prepared in methanol diluent at the quantity of $235 \mathrm{ppm}$. The working ELMS, ILMS and MLMS solution was also prepared in methanol diluent from stock solution at a specification limit quantity of $18.75 \mathrm{ppm}$. Six calibration solutions of ELMS, ILMS and MLMS at various levels (ELMS - 0.0115 to $0.0767 \mathrm{ppm}$, ILMS - 0.0111 to $0.0738 \mathrm{ppm}$ and MLMS - 0.0129 to $0.0858 \mathrm{ppm}$ ) were made in methanol diluent from serial dilution of stock solution.

\section{ATC Sample Solution}

ATC was dissolved in methanol diluent at 2000 ppm ATC concentration.

\section{Quantification of ELMS, ILMS and MLMS in ATC Sample}

Conditioned the column at $310^{\circ} \mathrm{C}$ for approximately $30 \mathrm{~min}$. Allowed the gas chromatograph to get equilibrated at $40^{\circ} \mathrm{C}$ till a sturdy baseline was obtained (at least approximately for $30 \mathrm{~min}$ ). After the system has been equilibrated, injected methanol diluent blank solution $(\mathrm{n}=1)$, and working ELMS, ILMS and MLMS solution $(6=6)$ and ATC sample solution $(n=1)$ into the gas chromatograph system. Using conditions described in the section "Instrumentation employed and conditions for quantification", determined the peak areas of ELMS, ILMS and MLMS. The ELMS, ILMS and MLMS content (ppm) of the ATC sample solution was determined utilizing the below-given formula:

$$
\text { Impurity } \left.(\mathrm{ppm})=\left[\left(\mathrm{A}_{\mathrm{IT}}-\mathrm{A}_{\mathrm{BL}}\right) /\left(\mathrm{A}_{\mathrm{STD}}-\mathrm{A}_{\mathrm{BL}}\right)\right] \mathrm{X}\left(\mathrm{Wt}_{\mathrm{STD}} / \mathrm{Dil}_{\mathrm{STD}}\right) \mathrm{X}\left(\mathrm{Dil}_{\mathrm{TEST}} / \mathrm{Wt}_{\mathrm{TEST}}\right)\right] \mathrm{X} \mathrm{P} \text { X10000 }
$$

In above equation, $A_{B L}=$ Response area of impurity in methanol diluent blank chromatogram; $A_{I T}=$ Response area of ELMS, ILMS and MLMS in test solution chromatogram; $A_{\text {STD }}=$ Average response area of impurity in working ELMS, ILMS and MLMS solution; $\mathrm{Wt}_{\mathrm{STD}}=$ Weight quantity of impurity in working solution; $\mathrm{Wt}_{\mathrm{TEST}}=$ Weight quantity of ATC in sample solution; Dil $\mathrm{STD}_{\mathrm{ST}}=$ Dilution factor of working solution; Dil $_{\text {TEST }}=$ Dilution factor of ATC sample solution; $\mathrm{P}=$ Potency of impurities.

\section{Method Optimization}

\section{RESULTS AND DISCUSSION}

Experimental trial studies were carried out to optimize the condition requirements of gas chromatography, so that better resolution was accomplished between ELMS, ILMS and MLMS. Initial investigations were pursued employing various columns with distinct chemistries including DB-624, DB-5 (film thickness of 
0.25 micron, length of $30 \mathrm{~m}$ and internal diameter of $0.32 \mathrm{~mm}$ ). Parameters of GC-MS including the program of oven temperature and flow rate have been configured. The influence of constant pressure and constant mode of flow also was judged. Trials on DB-5 column with ultimate optimized oven program and flow rate (see section "Instrumentation employed and conditions for quantification") were found to be better compared to the evaluated trials. The identification of ELMS, ILMS and MLMS was done in chosen ion mode of monitoring (ions $-79 \mathrm{~m} / \mathrm{z}$ for ELMS, $80 \mathrm{~m} / \mathrm{z}$ for MLMS and $123 \mathrm{~m} / \mathrm{z}$ for MLMS).

\section{Validation}

\section{System Suitability}

The system suitability was judged by analyzing the methanol diluent blank and six times working ELMS, ILMS and MLMS solution. The relative standard deviation for ELMS (5.3\%), ILMS (6.1\%) and MLMS $(5.1 \%)$ response peak areas from six injections were fewer than $15 \%$, suggesting suitability for the system to evaluate ELMS, ILMS and MLMS simultaneously.

\section{Specificity/Selectivity}

The specificity/selectivity was judged by analyzing the methanol diluent blank, working ELMS, ILMS and MLMS solution, ATC control sample solution and ATC spiked with ELMS, ILMS and MLMS. The quantities of ELMS, ILMS and MLMS in working and spiked ATC solutions were $18.75 \mathrm{ppm}$. The archetypal chromatograms of methanol diluent blank, working ELMS, ILMS and MLMS solution and ATC spiked with ELMS, ILMS and MLMS were put on view in Fig. -1. As seen by Fig. -1, there's no noticeable interference at retention periods of ELMS, ILMS, and MLMS in chromatograms of methanol diluent blank and ATC control sample solution.
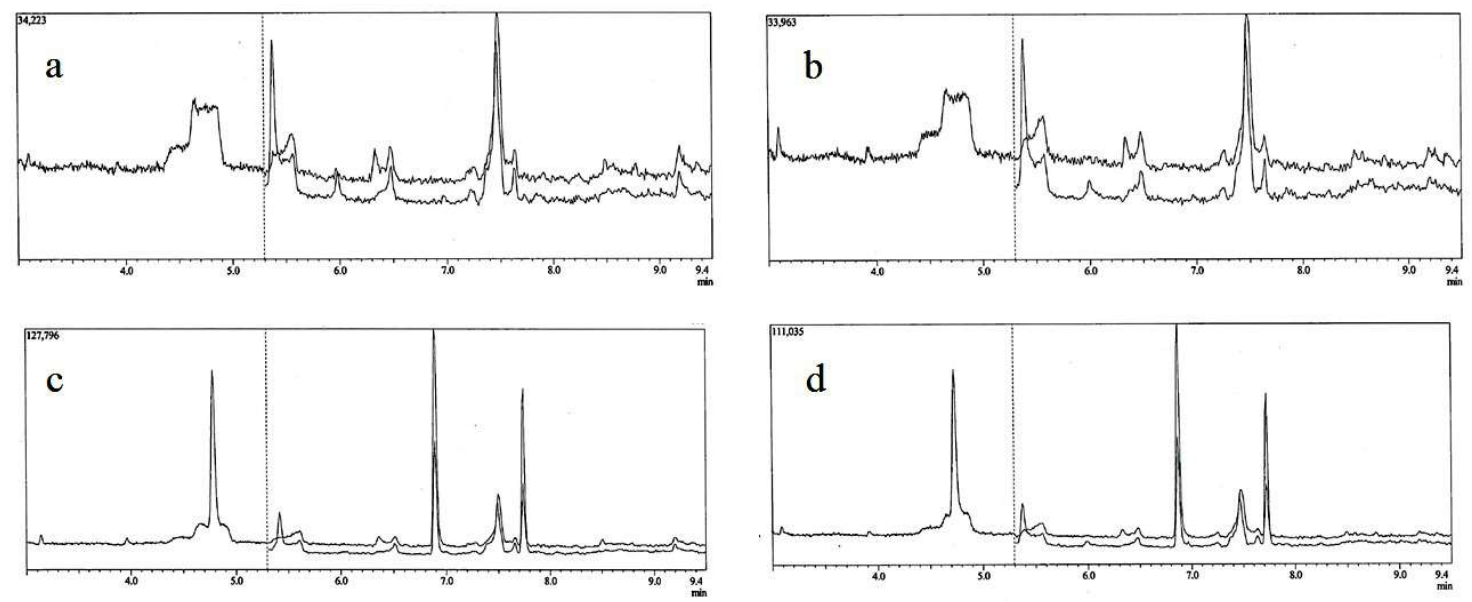

Fig. -1: Chromatograms of [a] Methanol Diluent Blank [b] ATC Control Sample Solution [c] Working ELMS, ILMS and MLMS Solution [d] ATC Spiked with ELMS, ILMS and MLMS

Limits of Detection (Ld) and Quantification (Lq)

Ld confirmation was done by visual response detection at $0.5 \%, 5.0 \%, 10.0 \%, 15.0 \%$, and $25.0 \%$ quantity of MLMS, ELMS and ILMS, and concentration that was reliably detected visually was assessed as Ld. The $\mathrm{Lq}$ and $\mathrm{Ld}$ were assessed to be precise by injecting six replicate injections. The Ld values were $0.004 \mathrm{ppm}$ (concentration of $2.0 \mathrm{ppm}$ for test sample) for MLMS and ELMS, and $0.004 \mathrm{ppm}$ (concentration of $2.1 \mathrm{ppm}$ for test sample) for ILMS. The Lq values were $0.013 \mathrm{ppm}$ (concentration of $8.1 \mathrm{ppm}$ for test sample) for MLMS, $0.012 \mathrm{ppm}$ (concentration of $6.8 \mathrm{ppm}$ for test sample) for ELMS, and $0.011 \mathrm{ppm}$ (concentration of $7.7 \mathrm{ppm}$ for test sample) for ILMS. The Ld and Lq values were confirmed by analyzing six times the ELMS, ILMS and MLMS solutions prepared at a concentration of $\mathrm{Ld}$ and Lq values. The relative standard deviation for ELMS (4.5\% at Lq and 8.6 at Ld), ILMS (4.9\% at Lq and 8.9 at Ld) and MLMS (7.1\% at Lq and 8.2 at Ld) area response was fewer than 33\%, suggesting adequate Ld values and fewer than $15 \%$ suitability suggesting adequate $\mathrm{Lq}$ values for analysis. 
RASĀYAN J. Chem.

Vol. 14 | No. 2 |1081-1086| April - June | 2021

\section{Linearity}

Linearity was judged by analyzing five concentrations ranges from $\mathrm{LOQ}(\mathrm{Lq})$ to $200 \%$ of specification limit quantity (18.75 ppm) of ELMS (0.0115 to $0.0767 \mathrm{ppm}$ ), ILMS (0.0111 to $0.0738 \mathrm{ppm})$ and MLMS (0.0129 to $0.0858 \mathrm{ppm}$ ). The linearity graphs of ELMS, ILMS and MLMS were mapped between response areas and the respective concentrations. Squared correlation coefficient (correlation coefficient, slope, residual sum of the square, and Y-intercept) values for ELMS, ILMS and MLMS were calculated (Table-1). The squared correlation coefficient values for ELMS, ILMS and MLMS were more than 0.990, suggesting good linearity from LOQ to $200 \%$ of specification limit quantity.

Table-1: Values Confirming Linearity of ELMS, ILMS and MLMS

\begin{tabular}{c|c|c|c}
\hline Parameter & ELMS & ILMS & MLMS \\
\hline Linearity range & 0.0115 to $0.0767 \mathrm{ppm}$ & 0.0111 to $0.0738 \mathrm{ppm}$ & 0.0129 to $0.0858 \mathrm{ppm}$ \\
\hline Correlation coefficient & 0.999 & 0.999 & 0.999 \\
\hline Squared Correlation coefficient & 0.998 & 0.998 & 0.998 \\
\hline Slope & 2848990.48 & 1971999.09 & 1850934.46 \\
\hline Residual sum of square & 36812672.15 & 20529243.89 & 21566826.07 \\
\hline Y-Intercept & 6573.05 & 13164.76 & 10959.52 \\
\hline
\end{tabular}

\section{Precision}

The system precision was judged by analyzing the methanol diluent blank one time and six times working ELMS, ILMS and MLMS solution. The relative standard deviation for ELMS (5.3\%), ILMS (6.1\%) and MLMS (5.1\%) response peak areas from six injections were fewer than $15 \%$, suggesting precision for the system to evaluate ELMS, ILMS and MLMS simultaneously.

The method precision was judged by analyzing six times the ATC solution (2000 ppm) spiked with ELMS, ILMS and MLMS at specification limit quantity. The mean quantity for ELMS, ILMS and MLMS assessed are $18.8 \mathrm{ppm}, 18.6 \mathrm{ppm}$ and $18.6 \mathrm{ppm}$, respectively. Relative standard deviation values for ELMS, ILMS and MLMS were $1.1 \%, 0.9 \%$ and $0.6 \%$. The relative standard deviation from six quantifications was fewer than $20 \%$, suggesting reliability and repeatability in evaluating ELMS, ILMS and MLMS simultaneously. The intermediate precision/ruggedness was judged by analyzing six times the ATC solution (2000 ppm) spiked with ELMS, ILMS and MLMS at specification limit quantity by the different analyst $(\mathrm{n}=2)$ on a different day $(\mathrm{n}=2)$. The cumulative relative standard deviation values for 12 quantifications of ELMS, ILMS and MLMS were assessed (Table-2) and were found fewer than 20\%, suggesting intermediate precision/ruggedness in evaluating ELMS, ILMS and MLMS simultaneously.

Table-2: Confirming Intermediate Precision/Ruggedness for ELMS, ILMS and MLMS

\begin{tabular}{c|c|c|c|c|c|c}
\hline \multirow{2}{*}{ Parameter } & \multicolumn{3}{|c|}{ Impurity Quantity Determined (ppm) for Test Sample } \\
\cline { 2 - 7 } & \multicolumn{2}{|c|}{ MLMS } & \multicolumn{2}{c}{ ELMS } & \multicolumn{2}{c}{ ILMS } \\
\cline { 2 - 7 } & $\begin{array}{c}\text { Analyst 1 } \\
\text { and Day 1 }\end{array}$ & $\begin{array}{c}\text { Analyst 2 and } \\
\text { Day 2 }\end{array}$ & $\begin{array}{c}\text { Analyst 1 and } \\
\text { Day 1 }\end{array}$ & $\begin{array}{c}\text { Analyst 2 } \\
\text { and Day 2 }\end{array}$ & $\begin{array}{c}\text { Analyst 1 and } \\
\text { Day 1 }\end{array}$ & $\begin{array}{c}\text { Analyst 2 } \\
\text { and Day 2 }\end{array}$ \\
\hline Mean* & 18.6 & 17.9 & 18.8 & 18.5 & 18.6 & 17.6 \\
\hline \% RSD & 0.6 & 1.3 & 1.1 & 1.4 & 0.9 & 1.6 \\
\hline Overall mean & \multicolumn{3}{|c|}{18.3} & \multicolumn{2}{c}{18.7} & \multicolumn{2}{c}{18.1} \\
\hline Overall\% RSD & \multicolumn{2}{|c|}{2.1} & \multicolumn{2}{c}{1.6} & 3.0 \\
\hline
\end{tabular}

* Mean of six quantifications

\section{Accuracy}

The accuracy was judged by analyzing three times the ATC solution (2000 ppm) spiked with ELMS, ILMS and MLMS at LOQ (ELMS - $4.98 \mathrm{ppm}$, ILMS - 5.16 ppm and MLMS - 5.08 ppm), 100\% (ELMS - 18.61 ppm, ILMS - $20.64 \mathrm{ppm}$ and MLMS - 20.32 ppm) and 150\% (ELMS - 29.85 ppm, ILMS - $30.96 \mathrm{ppm}$ and MLMS $-30.49 \mathrm{ppm}$ ) of specification limit quantity. The mean percent quantity ELMS, ILMS and MLMS recovered at three studied levels were assessed (Table-3). The mean percent quantities of ELMS, ILMS and MLMS recovered from three quantifications were within 70 to $130 \%$, suggesting accurateness in evaluating ELMS, ILMS and MLMS simultaneously. 
RASĀYAN J. Chem.

Vol. 14 | No. 2 |1081-1086| April - June | 2021

Table-3: Confirming Accuracy for ELMS, ILMS and MLMS

\begin{tabular}{l|c|c|c|c}
\hline \multirow{2}{*}{ Solvent } & \multicolumn{4}{|c}{ Mean percent recovered* } \\
\cline { 2 - 5 } & LOQ Level & $100 \%$ level & $150 \%$ level & Overall Mean \\
\hline MLMS & 116.9 & 90.0 & 91.8 & 99.6 \\
\hline ELMS & 119.1 & 99.2 & 94.4 & 104.2 \\
\hline ILMS & 116.7 & 87.8 & 88.6 & 97.7 \\
\hline
\end{tabular}

\section{CONCLUSION}

In the investigation, GC-MS methodology development and validation for the simultaneous determination of ELMS, ILMS and MLMS contaminants in ATC were done. Based on the gathered results through validation, it was concluded that GC-MS methodology for determining ELMS, ILMS and MLMS simultaneously in ATC is specific, precise, sensitive, linear and accurate. Therefore, this GC-MS methodology can be employed for quality control of studied impurities in ATC.

\section{ACKNOWLEDGEMENT}

The Authors thank Mr. Pavan of Sun Bio limited for providing gift samples and impurities of atorvastatin calcium for the research project and providing the necessary support and infrastructure to conduct the experimentation.

1. D. J. Snodin, Regulatory Toxicology and Pharmacology, 45, 79(2006), DOI: $10.1016 /$ j.yrtph.2006.02.003

2. S. L. Coffing, M.O. Kenyon, J.I. Ackerman, T.J. Shutsky, K.L. Dobo, Environmental and Molecular Mutagenesis, 56, 322 (2015), DOI:10.1002/em.21910

3. Methyl Methanesulfonate, International Agency for Research on Cancer (IARC) - Summaries and Evaluations, Vol. 71, p.1059 (1991).

4. E. Gocke, H. Bürgin, L. Müller, T. Pfister, T. Toxicology Letters, 190, 254(2009), DOI: 10.1016/j.toxlet.2009.03.016

5. K.L. Dobo, N. Greene, M.O. Cyr, S. Caron, W.W. Ku, Regulatory Toxicology and Pharmacology, 44, 282(2006), DOI:10.1016/j.yrtph.2006.01.004

6. Guidelines on the Limits of Genotoxic Impurities. Committee for Medicinal Products for Human Use [CHMP]. European Medicines Agency [EMEA], London (2006).

7. Genotoxic and Carcinogenic Impurities in Drug Substances and Products: Recommended Approaches; US Department of Health and Human Services, Food and Drug Administration, Center for Drug Evaluation and Research (CDER): Silver Spring, MD, USA (2008).

8. R. Kroes, J. Kleiner, A. Renwick, Toxicological Sciences, 86, 226(2006), DOI:10.1093/toxsci/kfi169

9. J.T. Davies, S.R. Delfino, C.E. Feinberg, M.F. Johnson, V.L. Nappi, J.T. Olinger, A.P. Schwab, H.I. Swanson, Lipid Insights, 9, 13(2016), DOI:10.4137/LPI.S37450

10. S. Ramkumar, A. Raghunath, S. Raghunath, Acta Cardiologica Sinica, 32, 631(2016), DOI:10.6515/acs20160611a

11. L. Müller, R.J. Mauthe, C.M. Riley, Regulatory Toxicology and Pharmacology, 44, 198(2006), DOI: $10.1016 /$ j.yrtph.2005.12.001

12. V. Sathiyanarayanan, H. Venkatasubramanian, D. Easwaramoorthy, Rasayan Journal of Chemistry, 12, 2141(2019), DOI: 10.31788/RJC.2019.1245419

13. L. P. Magar, B. H. Zaware, C. J. Laheru, D. Singh, S.J. Takate, M.K.Gupta,Rasayan Journal of Chemistry,13, 940(2020), DOI:10.31788/RJC.2020.1325632

14. S. Mullangi, K. Ravindhranath, Rasayan Journal of Chemistry, 13(3), 1662(2020), DOI: $10.31788 /$ RJC.2020.1335819

15. P. R. Kakadiya, T.G. Chandrashekhar, S. Ganguly, D.K. Singh, V. Singh, Analytical Chemistry Insights, 6, 21(2011), DOI:10.4137/ACI.S6471

16. J. Zhou, J. Xu, X. Zheng, W. Liu, F. Zheng, Journal of Separation Science, 40, 3414(2017), DOI: $10.1002 /$ jssc. 201700543 
RASĀYAN J. Chem.

Vol. 14 | No. 2 |1081-1086| April - June | 2021

17. K. Ramakrishna, N.V. Raman, K.M. Rao, A.V. Prasad, K.S. Reddy, Journal of Pharmaceutical and Biomedical Analysis, 46, 780(2008), DOI:10.1016/j.jpba.2007.11.013

18. C. Zhang, L. Huang, Z. Wu, C. Chang, Z. Yang, Journal of Separation Science, 39, 3558(2016), DOI: $10.1002 /$ jssc. 201600389

19. Z. Mengmeng, P. Hongjuan, C. Jia, L. Xiaohui, Chinese Journal of Pharmaceuticals, 46, 55(2015).

20. S. Hussain, T. Shaikh, A. Gosar, International Journal of Innovative Pharmaceutical Sciences and Research, 3, 1471(2015).

21. P. Veenaeesh, G. Manikumar, P. Manjusha, A. Padmasri, International Journal of Pharma Research and Review, 3, 11(2014).

22. C. Sitaram, R.B. Rupakula, B.N. Reddy, C.S. Sastry, Indian Journal of Pharmaceutical Sciences, 73, 107(2011), DOI: 10.4103/0250-474X.89769

[RJC-6208/2020] 